\title{
EVALUATION OF ANTIBACTERIAL AND ANTIFUNGAL ACTIVITIES OF ETHANOLIC POLYHERBAL EXTRACT
}

\author{
*N. Deattu ${ }^{1}$, L. Suseela ${ }^{2}$, N. Narayanan ${ }^{3}$ \\ ${ }^{1}$ Department of Pharmaceutics, College of Pharmacy, Madras Medical College, Chennai-03, INDIA \\ ${ }^{2}$ Jamia Salafia College of Pharmacy, Calicut, Kerala, INDIA \\ ${ }^{3}$ Jaya College of Pharmacy, Tiruninravur, Chennai, INDIA \\ *Corresponding Author's Phone: 9884140202, E-mail i.d: ndeattu@gmail.com
}

Received 04 Oct 2012; Review Completed 18 Oct 2012; Accepted 01 Nov 2012, Available online 15 Nov 2012

\begin{abstract}
Antimicrobial activity of an ethanolic polyherbal extract was examined against the bacterial strains, Escherichia coli, Proteus mirabilis, Gardnerella vaginalis and Pseudomonas aeruginosa and the fungal strains, Candida albicans and Aspergillus niger using disc diffusion method. The polyherbal extract was prepared from the combined ethanolic extracts of Saraca indica, Symplocos racemosa, Hemidesmus indicus, Aloe vera, Asteracantha longifolia, Erythrina indica and Tribulus terrestris. Antibacterial activity was determined using Mueller Hinton Agar (MHA) medium and antifungal activity was studied using Potato dextrose agar (PDA) medium. The polyherbal extract showed significant antimicrobial activity against the tested microorganisms. The minimum inhibitory concentration (MIC) value was also determined which was found to be $1 \mathrm{mg} / \mathrm{ml}$ against the selected microorganisms.

Key Words: Antibacterial activity, antifungal activity, polyherbal extract, minimum inhibitory concentration
\end{abstract}

\section{INTRODUCTION}

Herbal medicine, sometimes referred to as Herbalism or Botanical Medicine, is the oldest form of healthcare known to mankind. Herbs had been used by all cultures throughout history for their therapeutic or medicinal value. A herb as a whole or plant part is valued for its medicinal, aromatic or savoury qualities. Herbal plants contain therapeutically active chemical substances that act upon the body ${ }^{l}$. Many drugs commonly used today are of herbal origin. Herbal medicine is a major component in all indigenous traditional medicine and a common element in Ayurvedic, Homeopathic, Naturopathic, Traditional oriental and Native Indian medicine.

Historically, natural products, derived mainly from plant sources, have proved to be a fruitful source of new therapeutic agents. Herbal medicines are frequently considered to be less toxic and free from side effects than synthetic ones ${ }^{2-4}$. With the advancement of phytochemical knowledge, many active ingredients responsible for therapeutic action have been identified and isolated from plant sources. Better therapeutic effect, good patient compliance and cost effectiveness are the reasons for choosing drugs from natural origin.

An herbal formula consists of a selective combination of individual herbal ingredients that are formulated for a specific ailment or group of disease conditions. When herbs are combined together, they become more potent and effective within the body than single herb due to their activating or catalyzing influence upon one another. These combinations act as powerful catalysts with synergistic effects in order to activate individual healing energies which permeate the entire organism and reside in each and every cell in our body.

In the present work a polyherbal extract has been prepared from the combined ethanolic extracts of various plants viz., Saraca indica, Symplocos racemosa, Hemidesmus indicus, Aloe vera, Asteracantha longifolia, Erythrina indica and Tribulus terrestris. The polyherbal extract was screened for antibacterial and antifungal activities against selected microorganisms.

\section{MATERIALS AND METHODS}

\section{Collection of plant material}

The plants were collected from Palode, Kerala and Papanasam, Tamil Nadu. The plants were authenticated by Botanical Survey of India, Coimbatore. The extraction process was carried out in Rumi Herbals R \& D, Chennai.

\section{Preparation of extract}

The collected plant parts were cleaned and shade dried. The dried plant parts were coarsely powdered. Equal portions by weight of all the ingredients were homogenously mixed and subjected to soxhlet extraction using ethanol. The extract obtained was evaporated in rotary evaporator to get a powdery mass. The powder extract obtained was then subjected to phytochemical analysis to detect the chemical constituents present.

The phytoconstituents present in the extract was detected by performing preliminary phytochemical tests. The detection of various phytoconstituents was carried out by performing qualitative chemical tests. The results of phytochemical analysis showed the presence of alkaloids, phenolic compounds, tannins, saponins, phytosterols, gums, mucilage, carbohydrates, proteins, amino acids, triterpenoids and flavones.

\section{Preparation of Inoculum}

Stock cultures were maintained at $4{ }^{\circ} \mathrm{C}$ on slopes of nutrient agar. Active cultures for experiments were prepared by transferring a loopful of cells from the stock cultures to test tubes of Mueller-Hinton Broth (MHB) for bacteria and Sabouraud Dextrose Broth (SDB) for fungi that were incubated without agitation for $24 \mathrm{~h}$ at $37^{\circ} \mathrm{C}$ and $25^{\circ} \mathrm{C}$ respectively. The cultures were diluted with fresh MuellerHinton and Sabouraud dextrose broth to achieve optical 
Deattu et al

Journal of Drug Delivery \& Therapeutics; 2012, 2(6), 53-55

densities corresponding to $10^{6}$ colony forming units $(\mathrm{CFU} / \mathrm{ml})$ for bacteria \& $10^{5}$ spore/ml for fungal strains.

\section{Antibacterial activity}

The effect of the polyherbal extract was studied on several bacterial strains by Disc diffusion method. ${ }^{5-7}$

\section{Culture Medium}

Mueller Hinton Agar (MHA) (B.No LOT 0000054948, Exp. date Mar. 2013)

Nutrient Broth(B.No. LOT0000010128, Exp.Dat 01/2013)

\section{Mueller Hinton Agar Medium}

One liter of MHA medium was prepared by dissolving $33.9 \mathrm{~g}$ of the commercially available Mueller Hinton Agar Medium (HiMedia) in $1000 \mathrm{ml}$ of distilled water. The dissolved medium was autoclaved at $15 \mathrm{lbs}$ pressure at $121^{\circ} \mathrm{C}$ for 15 min. The autoclaved medium was mixed well and poured onto $100 \mathrm{~mm}$ petriplates $(25-30 \mathrm{ml} /$ plate $)$ while still molten.

\section{Nutrient broth}

One liter of nutrient broth was prepared by dissolving $13 \mathrm{~g}$ of commercially available nutrient medium (HiMedia) in $1000 \mathrm{ml}$ distilled water and boiled to dissolve the medium completely. The medium was dispensed as desired and sterilized by autoclaving at $15 \mathrm{lbs}$ pressure $\left(121^{\circ} \mathrm{C}\right)$ for 15 min.

\section{Bacterial Strains}

\begin{tabular}{|c|c|c|}
\hline S.No & Bacterial Pathogen & Code Number \\
\hline 1 & Proteus mirabilis & RHPM001 \\
\hline 2 & Gardnerella vaginalis & RHGV001 \\
\hline 3 & Escherichia coli & RHEC001 \\
\hline 4 & Pseudomous aeroginosa & RHPA001 \\
\hline
\end{tabular}

\section{Method}

Growth inhibition activities for polyherbal extract against Escherichia coli (RHEC001), Pseudomonas aeruginosa (RHPA001), Proteus mirabilis (RHPM001) and Gardnerella vaginalis (RHGV001) were tested using disc diffusion method. One milliliter of inoculum suspension was used to inoculate by flooding the surface of Mueller-Hinton Agar petridishes. Excess liquid was airdried under a sterile hood. Three different dilutions of extracts (1000, 2000 and 3000 $\mu \mathrm{g} /$ disc) and Ciprofloxacin standard (100 $\mu \mathrm{g} / \mathrm{disc})$ were loaded on $6 \mathrm{~mm}$ sterile disc. Dimethylsulphoxide (DMSO) was used as negative control. The loaded disc was placed on the surface of medium and the compound was allowed to diffuse for $5 \mathrm{~min}$ and the plates were kept for incubation at $37^{\circ} \mathrm{C}$ for $24 \mathrm{~h}$. At the end of incubation, minimum inhibitory concentration and inhibition zones formed around the disc were measured with transparent ruler in $\mathrm{mm}$. The experiments were conducted in triplicate.

\section{Determination of MIC}

$1 \mathrm{ml}$ of standard test inoculum of bacterial suspension was added to the tubes containing $1 \mathrm{ml}$ of broth with different concentration of PHE. The tubes were incubated at $37^{\circ} \mathrm{C}$ for $24 \mathrm{~h}$. Subcultures were made from these tubes on Mueller Hinton Agar Medium and the presence, reduction or absence of growth was observed. If growth was observed, the particular compound was considered as inactive against the particular organism. If the growth was absent, the particular concentration of antibacterial agent was considered as effective in killing the microorganism. MIC is read as lowest concentration of antibacterial agent that inhibits the visible

\section{Method}

Three different dilutions of extracts (1000, 2000 and 3000 $\mu \mathrm{g} /$ disc $)$ and Ketoconazole standard $(20 \mu \mathrm{g} /$ disc $)$ were loaded on $6 \mathrm{~mm}$ sterile disc. The loaded disc was placed on the surface of medium and the compound was allowed to diffuse for $5 \mathrm{~min}$ and the plates were kept for incubation at $30^{\circ} \mathrm{C}$ for $72 \mathrm{~h}$. DMSO was used as the negative control. At the end of incubation, MIC and inhibition zones formed around the disc were measured with transparent ruler in $\mathrm{mm}$. All tests were assayed in triplicate.

\section{Statistical Analysis}

Results are expressed as the mean value \pm standard error of mean (S.E.M.). Significant difference between control and experimental groups was assessed by student's t test.

\section{Determination of MIC}

After preparation of a suspension of the fungus, the stock solution of these essences was prepared with DMSO. Then 1 $\mathrm{ml}$ of this stock solution was combined with Sabouraud dextrose agar medium to prepare diluted compound. $1 \mathrm{ml}$ Sabouraud broth was added to 11 tubes and $1 \mathrm{ml}$ of diluted compound added to the first tube and after shaking, 1 $\mathrm{ml}$ of this solution added to the second tube. This work was continued to $9^{\text {th }}$ tube. Finally, $1 \mathrm{ml}$ of mixture of essence diluted compound and culture medium was removed from number 9 tube. After this, $50 \mu \mathrm{L}$ of fungal suspension was added to first 10 tubes and then these tubes were incubated at $37^{\circ} \mathrm{C}$

$24 \mathrm{~h}$. After incubation the tubes were examined for microbial growth by observing turbidity after 24,48 and $72 \mathrm{~h}$. The MIC 
values were interpreted as the highest dilution of the sample which showed no growth. After $24 \mathrm{~h}$, concentration of that tube in which there is growth of one or two colonies was considered as the MIC. In this test, the $11^{\text {th }}$ tube is negative blank and $10^{\text {th }}$ tube is positive blank.

\section{RESULTS AND DISCUSSION}

The antibacterial activity was studied in Muller Hinton Agar medium by Disc diffusion method using Ciprofloxacin as standard. The bacterial strains used were Proteus mirabilis, Gardnerella vaginalis, Escherichia coli and Pseudomonas areuginosa. The extract showed good antibacterial activity. The MIC was found to be $1 \mathrm{mg} / \mathrm{ml}$ for all the bacterial strains used.

Antifungal activity was studied using Potato Dextrose Agar medium by Disc diffusion method using Ketoconazole as standard. The fungal strains used were Aspergillus niger and Candida albicans. The extract exhibited significant antifungal activity. The MIC value was found to be $1 \mathrm{mg} / \mathrm{ml}$ for both Aspergillus niger and Candida albicans. The zone of inhibition produced by the polyherbal extract with the selected organisms and the MIC values are shown in table 1.

The antimicrobial properties of the polyherbal extract may be attributed to the presence of alkaloids, flavonoids, saponins and tannins and is confirmed by the results of phytochemical analysis. The antimicrobial action of these compounds is well-known and is related to their ability to denature proteins, which in general renders them to be classified as surfaceactive agents.

Saponins have been reported to possess a wide range of biological activities. The mode of action of antibacterial effects of saponins seem to involve membranolytic properties, rather than simply altering the surface tension of the extracellular medium, thus being influenced by microbial population density.

Flavonoids are naturally occurring phenols which possess numerous biological activities including anti-inflammatory, antiallergic, antithrombotic and vasoprotective effects. Since they are known to be synthesized by plants in response to microbial infection, it should not be surprising that they have been found in vitro to be effective antimicrobial substances against a wide array of microorganisms. Their activity is probably due to their ability to complex with extracellular and soluble proteins and to complex with bacterial cell walls. More lipophilic flavonoids may also disrupt microbial membranes.

Alkaloids isolated from plant are commonly found to have antimicrobial properties. The mechanism of antimicrobial action is attributed to their ability to intercalate with DNA.

The antifungal activity may be attributed to various chemicals detectable in the extract such as saponins. The action mechanisms of saponins may lie in damage to the membrane and leakage of cellular materials, ultimately leading to cell death.

Table 1: Zone of inhibition against selected microorganisms and MIC values

\begin{tabular}{|c|c|c|c|c|c|c|c|}
\hline \multirow[b]{2}{*}{ Sample } & \multirow[b]{2}{*}{ Concentration $(\mu \mathrm{g} / \mathrm{disc})$} & \multicolumn{6}{|c|}{ Zone of inhibition ( in mm) } \\
\hline & & P.mirabilis & G.vaginalis & E.coli & P.aeruginosa & C.albicans & A.niger \\
\hline DMSO & 300 & - & - & - & - & - & - \\
\hline Ciprofloxacin & 100 & $12 \pm 0.57$ & $10 \pm 0.33$ & $16 \pm 0.57$ & $14 \pm 0.00$ & NA & NA \\
\hline Ketoconazole & 20 & NA & NA & NA & NA & $12 \pm 0.33$ & $10 \pm 0.00$ \\
\hline PHE & $\begin{array}{l}1000 \\
2000 \\
3000\end{array}$ & $\begin{array}{c}6 \pm 0.57^{\mathrm{a}} \\
8 \pm 0.33^{\mathrm{a}} \\
10 \pm 0.57^{\mathrm{a}}\end{array}$ & $\begin{array}{l}2 \pm 0.33^{\mathrm{a}} \\
4 \pm 0.33^{\mathrm{a}} \\
8 \pm 0.34^{\mathrm{a}}\end{array}$ & $\begin{array}{l}10 \pm 0.57^{\mathrm{a}} \\
12 \pm 0.33^{\mathrm{a}} \\
14 \pm 0.11^{\mathrm{a}}\end{array}$ & $\begin{array}{c}8 \pm 0.34^{\mathrm{a}} \\
10 \pm 0.33^{\mathrm{a}} \\
12 \pm 0.57^{\mathrm{a}}\end{array}$ & $\begin{array}{c}5 \pm 0.57^{\mathrm{a}} \\
8 \pm 0.34^{\mathrm{a}} \\
10 \pm 0.33^{\mathrm{a}}\end{array}$ & $\begin{array}{l}4 \pm 0.34^{\mathrm{a}} \\
6 \pm 0.57^{\mathrm{a}} \\
8 \pm 0.33^{\mathrm{a}}\end{array}$ \\
\hline & MIC & $1 \mathrm{mg} / \mathrm{ml}$ & $1 \mathrm{mg} / \mathrm{ml}$ & $1 \mathrm{mg} / \mathrm{ml}$ & $1 \mathrm{mg} / \mathrm{ml}$ & $1 \mathrm{mg} / \mathrm{ml}$ & $1 \mathrm{mg} / \mathrm{ml}$ \\
\hline
\end{tabular}

Values are mean $\pm S E M, n=6 . t$-value represents significance at ${ }^{a} p<0.05$ when compared with solvent control group

\section{CONCLUSION}

The polyherbal extract was found to possess significant antibacterial and antifungal activities. Thus it may be concluded that the antimicrobial properties of the polyherbal extract is due to the presence of the phytoconstituents present in the extract.

\section{ACKNOWLEDGEMENTS}

We are thankful to Rumi Herbals Research and Development, Chennai - 37 for providing us the necessary materials and facilities required for our research work.

\section{REFERENCES}

1. Moquin B, Blackman MR, Mitty E, Flores S, Complementary and alternative medicine, Geriatr Nurs, 2009, 30(3), 196-203

2. Satyavati GV, Raina MK, Sharma M. Medicinal Plants of India, Indian Council of Medical Research. New Delhi: 1987.P. 67-70

3. Benthold Bond and Annie. Basics for the home, simple solutions for less toxic living. New York: Three Rivers Press; 1999. P.15-23

4. Brent A Bauer, Herbal medicine the good, the bad and the ugly, So Cra Source, 2003, 8, 27-30

5. Wayne PA, National committee for clinical Laboratory Standard, In performance standards for antimicrobial disk susceptibility test, Sixth approved standard.1997.M2-A6
6. Pabbithi Sathya Chethan, Gopal Muruganathan, Kethini Komaleeawari, Evaluation of antimicrobial activity of methanolic extract fractions of Delonix elata bark, IJRAP, 2012, 3(3), 425-427

7. Ilias faiza, Kholkhal wahiba, Gaouar Nassira et al, Antibacterial and antifungal avtivity of olive (Olea europara L) from Algeria, J.Microbiol Biotech Res,2011, 1(2), 69-73

8. Ashish Sethi, Sharma RA, Antibacterial and antifungal avtivity of various whole plant extract of Aerva tomentosa forsk (Amaranthaceae), Int J Pharm Bio Sci, 2011, 2(3), 184-192

9. Shiv Shankar Goutham, Navneet, Sanjay Kumar, Prabhat, Screening of antibacterial avtivity of Nepeta ciliaris benth against respiratory tract pathogens, Kathmandu Univ J Sci Eng Tech,2012, 8(1), 100-103 